\title{
Practical Simplified Computing Method of Natural Vibration Frequency of Cable-stayed Bridge during Construction Stage
}

\author{
Xingnai Wang \\ Chang'an University
}

\begin{abstract}
In this paper, the vibration analysis model of the cable-stayed bridge is established by using double-mass method, and the formula for calculating its natural frequency during construction is deduced. On this basis, the formula is simplified to obtain the estimation formula of the natural vibration frequencies of the cable-stayed bridge during construction. The structure analysis software MIDAS Civil is used to establish the three-dimensional finite element model of the cable-stayed bridge of Jinan Qihe Yellow River Bridge to analyze the vibration characteristics of Qihe Yellow River Bridge during the construction stage, carry on the spot tracking of the modal test of the construction phase, and at the same time calculate the frequency by using the double-mass method and the estimation formula. The double-mass vibration model, the natural frequency estimation formula, the finite element method analysis and the field modal test results are compared and analyzed. Both the test results and the calculated results show that the finite element method can accurately simulate the actual force state of the bridge, and the double-mass model and the estimation formula provide a more accurate and efficient method for calculating the natural vibration frequencies, which provides reference for guiding design and construction monitoring work of the cablestayed bridge.
\end{abstract}

Keywords-simplified computing method; cable-stayed bridge; construction stage; natural vibration frequency; double-mass model; estimation formula; finit element method; modal experiment

\section{INTRODUCTION}

The vibration frequency, mode and damping ratio are three main indexes reflecting the dynamic performance of the structure, and also a representation of the overall state of the structure. The structural system, wind resistance and seismic performance of the cable-stayed bridge are closely related to the dynamic characteristics of the structure.

The frequency and mode of vibration have nothing to do with external disturbance, only depends on the mass distribution and flexibility coefficient of the structure, which reflects the intrinsic dynamic characteristics of the structure itself. With the increase of the stiffness of the structure, the natural frequencies of the vibration increase correspondingly, and the natural frequencies of the structure change. Two similar structures, if the frequency of vibration varies greatly, the dynamic performance is very different, whereas two of the structures with different appearances do not look the same, and if their natural frequencies are similar, their dynamic properties are basically consistent under dynamic loads. The test of natural vibration frequencies is mainly determined by the modal test.
The cable-stayed bridge is an ancient type, originating in 16th century, and is still developing to a larger span and larger scale. In the cantilever construction stage, the cable-stayed bridge belongs to the ultra-low frequency vibration structure with the poor structural stability, affected by the environment, construction load and cable force deviation, and with the increase of the cantilever length of the main girder, the natural vibration characteristic of the structure changes constantly, and the natural frequency analysis of the structure in the construction can be used as an auxiliary means for the bridge construction control. In this paper, the theoretical analysis and the modal analysis of the measured structure are made to study the dynamic characteristics of the construction phase, which provides a reference for the design of the monitoring and seismic performance of the bridge construction stage. By means of theoretical demonstration and experimental comparison, a simplified calculation formula of the natural vibration frequencies is obtained, which can be used to judge the dynamic performance of the cable-stayed bridge in construction stage quickly.

\section{RESEARCH STATUS OF DYNAMIC CHARACTERISTICS OF CABLE-STAYED BRIDGE}

At present, the research of vibration characteristic mainly aims at the finished bridge stage, mainly used in the health monitoring of the finished stage acceptance and the bridge operation stage as well as the research of the bridge earthquake resistance characteristic, but the construction stage mainly aims at the research of the cable tension, the tower's partial position and the main girder height.

The cantilever construction of the cable-stayed bridge is gradually advancing, as shown in Figure I, until the finished bridge stage is reached. No matter whether the structure of the cable-stayed bridge after the finished bridge is a tower girder consolidation or floating system, in the construction phase of temporary consolidation or permanent consolidation, the tower and the main girder are just the knot, fixed in the platform of the tower consolidation.

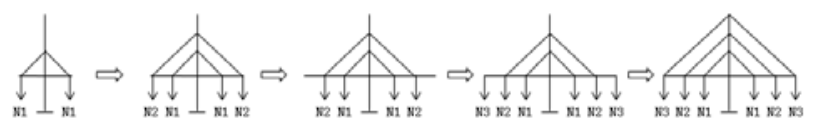

FIGURE I. SCHEMATIC DIAGRAM OF CONSTRUCTION STAGE OF CABLE-STAYED BRIDGE

There are three kinds of simplified calculation methods commonly used in calculating the dynamic characteristics of 
the cable-stayed bridge: the centralized mass method, generalized coordinate method and finite element method. The method of establishing the vibration equation of cable-stayed bridge is mainly based on the D'Alembert Principle, in which the flexibility method or stiffness method is used to establish the equilibrium equation.

In 1985, Xiang Haifan【1】 in Tongji University pointed out that in the finished bridge stage, the contribution of the first mode is an absolute advantage, that is, the longitudinal horizontal vibration, so that all the mass of the bridge deck is mainly on the top of the tower, and the own mass of the tower is converted to the equivalent mass, which is also on the top of the tower, forming an alternative system to establish a singlemass model (See Figure II).

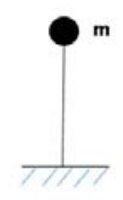

FIGURE II. SIMPLIFIED MODEL OF SINGLE-MASS MECHANICS

In 2005, Yuan Wancheng 【 2 】 in Tongji University established a simplified model of two-mass model mechanics on this basis (See Figure III).

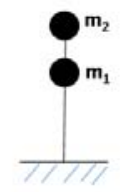

FIGURE III. SIMPLIFIED MODEL OF DUAL-MASS MECHANICS

In 2013, Song Yifan in Chang'an University also pointed out that for the high pier continuous rigid frame bridge, the vibration form of bridge is mostly the longitudinal floating vibration of piers, and the finite element method is used to analyze the characteristics of high pier vibration.

\section{CAlCulation of Double-Mass System IN CONSTRUCTION PHASE}

\section{A. The Establishment of Two-mass Vibration Model}

In the construction stage, the cantilever symmetrical construction is generally used in the cable-stayed bridge, only bearing the symmetrical constant deadweight instead of the automobile and the crowd load. Its simplified method of model is as follows.

1) Simplification of constraints: The connection between the tower and the pile cap is considered to be a rigid one, and so is the support (including temporary support) between the abutment and the main girder.

2) Simplification of bridge tower vibration model: Similar to the two-mass model of Tongji University, the mass and the position of the bridge tower with continuous mass distribution are equivalently converted to keep the total mass of the tower unchanged, and the position of action is placed at the center of gravity of the bridge tower. If the straight tower is equal cross-section, the position of the tower is in the third location between the bridge tower and the bearing platform.

3) Simplification of main girder vibration model: The continuously increasing total mass of the cantilever end of the main beam is kept unchanged. If there is no stretching cable in Section No. 0, the position of section No. 0 will remain unchanged at the actual deck position (See Figure. IV). After Section No. 1, with the tension of the cable-stayed bridge, the weight of the main beam is transferred from the cable to the bridge tower and it is acted upon the tower in the form of axial compression. Therefore, below the anchor point of the cable of the tower, the entire tower is under uniform compression, so the position of the action point along the axial pressure is in the half position below the anchor point of the cable (See Figure V).

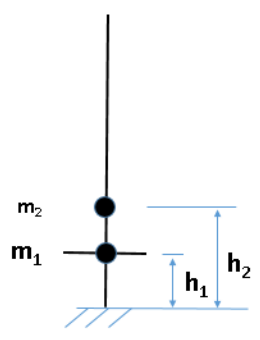

FIGURE IV. DOUBLE-MASS MODEL WITHOUT CABLE IN CONSTRUCTION PHASE

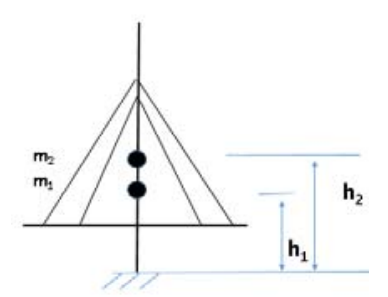

FIGURE V. DOUBLE-MASS MODEL WITH CABLE IN CONSTRUCTION PHASE

$\mathrm{m}_{2}$ : Tower's mass $\mathrm{m}_{2} \quad \mathrm{~m}_{1}$ : Girder's mass $\mathrm{m}_{1}$

Notes: $h 1$ and $h 2$ are respectively the weights of the tower and the main girder (including construction equipment above the main girder). In order to unify the formula, the height of the lower mass position is defined as $\mathrm{h} 1$, and the height of the higher position is defined as $\mathrm{h} 2$.

\section{B. The Solution of the Free Vibration Frequency of Two-mass Freedom}

The differential equation of free vibration established by the method of flexibility:

In the differential equation, $\delta_{\mathrm{ij}}$ is the flexibility coefficient. The solution of the differential equation is:

$$
\begin{aligned}
& y_{1}(t)=Y_{1} \sin (w t+\alpha) \\
& y_{2}(t)=Y_{2} \sin (w t+\alpha)
\end{aligned}
$$


Substituting the differential equation to get the following expression is:

$$
\begin{gathered}
\left(\delta_{11} m_{1}-\frac{1}{w^{2}}\right) Y_{1}+\delta_{12} m_{2} Y_{2}=0 \\
\delta_{21} m_{1} Y_{1}+\left(\delta_{22} m_{2}-\frac{1}{w^{2}}\right) Y_{2}=0
\end{gathered}
$$

In order to obtain the solution that is not zero, the coefficient determinant should be equal to zero, that is:

$$
\mathrm{D}=\left|\begin{array}{cc}
\delta_{11} m_{1}-\frac{1}{w^{2}} & \delta_{12} m_{2} \\
\delta_{21} m_{1} & \delta_{22} m_{2}-\frac{1}{w^{2}}
\end{array}\right|=0
$$

This is the frequency equation or characteristic equation expressed by the flexibility coefficient, which can be used to find two frequency values $\mathrm{w}_{1}$ and $\mathrm{w}_{2}$, and also $\mathrm{f}=\frac{\mathrm{w}}{2 \pi}$.

$$
\begin{aligned}
& \mathrm{f}_{1}=\frac{\omega_{1}}{2 \pi}=\frac{1}{2 \pi \sqrt{\left(\delta_{11} m_{1}+\delta_{22} m_{2}\right)+\sqrt{\left(\delta_{11} m_{1}+\delta_{22} m_{2}\right)^{2}-4\left(\delta_{11} \delta_{22}-\delta_{12} \delta_{21}\right) m_{1} m_{2}}}} \\
& \mathrm{f}_{2}=\frac{\omega_{2}}{2 \pi}=\frac{1}{\sqrt{2 \pi} \sqrt{\left(\delta_{11} m_{1}+\delta_{22} m_{2}\right)-\sqrt{\left(\delta_{11} m_{1}+\delta_{22} m_{2}\right)^{2}-4\left(\delta_{11} \delta_{22}-\delta_{12} \delta_{21}\right) m_{1} m_{2}}}}
\end{aligned}
$$

\section{Calculation Formula of Construction Phase}

Based on the derivation formula of the fundamental frequency of the two-mass system, it can be seen that the f1 value of the natural frequency is smaller than $\mathrm{f} 2$. The vibration frequency of the cable-stayed bridge in the construction stage is very small, the value 4 below the denominator is smaller, and many tests have found that the equivalent height of the main beam and the tower is not sensitive to the change of the calculated result in the calculation of $\delta_{i j}$ by the method of graph multiplication, so the formula is modified by the change of mass and the mass ratio of the tower, and the formula will be simplified as follows:

$$
f_{1}=\frac{w}{2 \pi}=\frac{1}{2 \pi \sqrt{\delta_{11} m_{1}+\delta_{22} m_{2}}} \sqrt[4]{\frac{m_{1}}{m_{2}}}
$$

\section{ENGINEERING APPLICATION}

The main bridge of Qihe Yellow River Highway Bridge is $840 \mathrm{~m}$ long, with the span distribution of $40+175+410+175+40 \mathrm{~m}$ and the deck width of 38.0 meters. The type of main bridge is the cable-stayed bridge with the twin-tower double cable-steel composite girder. 138 meters of the tower in height adopts the gate-shaped frame and the section of single chamber hollow box type. There are the 16 pairs of cables in the two-wire fan layout arranged on both sides of the tower. The steel main girder is connected to form a steel structure by the side steel box, beam and small longitudinal beam through the splicing plate and high-strength bolts. The girder width of the side steel box is is 2.8 meters wide, 3.0 3.056 meters high, with the roof thickness of $25 \mathrm{~mm}$, floor thickness of $35 \sim 45 \mathrm{~mm}$, and web thickness of $30 \mathrm{~mm}$ according to the different areas of stress(See Figure VI).

The vehicle load for the bridge design is the I-level highway with the wind resistance design standard for 100 years of the operation stage design reappearance period and the basic wind speed $28.6 \mathrm{~m} / \mathrm{s}$; during the construction stage, the design recurrence period is 10 years with the basic wind speed $22.2 \mathrm{~m} / \mathrm{s}$ (See Figure VII).

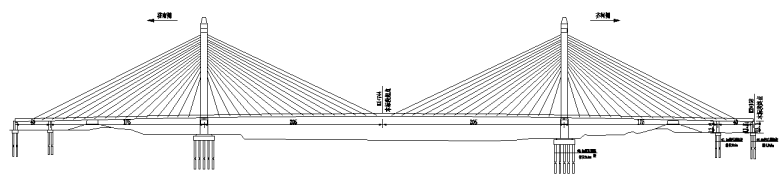

FIGURE VI. ELEVATION LAYOUT

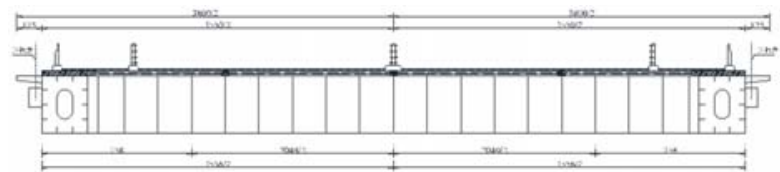

FIGURE VII. SECTIONAL DRAWING OF GIRDER

\section{A. The Establishment of Finite Element Model}

The accurate simulation of structural stiffness, mass and boundary conditions is the basis of structural dynamic analysis, and it should be ensured that these three aspects are in accordance with the actual situation when modeling.

The finite element model of the bridge is established by finite element program Midas CIVIL2015, using the model of fish bone shape, in which the main girder, tower and crossbeam are simulated by space finite element method, the cable is simulated by space truss element, and the cable is connected with the main beam, the tower and the crossbeam by the rigid arm, and the bottom of the tower pier is confined to the consolidation. Vertical and transverse constraints are applied to the corresponding positions of the main girder transition pier and auxiliary pier.

The constraint conditions of the model are as follows: (1) The column is embedded on the top of the platform; (2)The main girder is supported on the column beam; (3)There are the multiple row friction piles under the bearing platform of the main pier; (4)The auxiliary pier and the transitional pier are provided with the elastic connecting unit to simulate the support function, and (5)The rigid arm units are used in the connection between the cable and the main beam, the column and the column cross point.

\section{1) Main girder simulation}

When analyzing the dynamic characteristics of the concrete cable-stayed bridge, the main beam model can adopt many kinds of elements, including beam elements, shell element, entity unit and the combination form of these units. Too complex simulation of the main beam element will greatly increase the efficiency of the calculation, and it is not necessary to do it. Therefore, in view of the example, the main girder of the bridge is composed of the steel frame by the side steel box, the crossbeam and the small longitudinal beam through the connection of the splicing plate and the high- 
strength bolt, and above the steel frame, the precast bridge panel, the cast-in-place concrete wet joint, and the shear nail on the steel beam are formed as a whole to make up the steelconcrete composite beam system. In this paper, according to the principle of equivalence, the stiffness, mass and support condition of the main girder are abstracted and simplified reasonably, and the double main beam spine model with higher computational efficiency is simulated, and the plate element is used to simulate the precast bridge panel.

\section{2) Cable-stayed simulation}

After the load is applied, the shape and axis of the main components of the cable-stayed bridge will change greatly. After considering these changes, the force and deformation of the structure will no longer be the linear proportional relationship. The nonlinearity of the cable has great influence on the dynamic characteristics of the structure, so the nonlinear effect of the cable is considered in the paper. The axial force and the gravity droop effect of the cable show the obvious geometrical nonlinearity of the cable, which is generally considered by Ernst's equivalent elastic modulus:

$$
E_{e q}=\frac{E_{e}}{1+\frac{(\gamma l)^{2}}{12 \sigma^{3}} E_{e}}
$$

In the formula, Em is the equivalent elastic modulus of the stayed cable; Ee is the effective elastic modulus of the stayed cable; $\gamma$ is the gravity density of the cable; lis the horizontal projection length of the cable, and $\sigma$ is the initial stress of the cable.

In this paper, the truss element is used to simulate the cable, and the elastic model is modified by the above Ernst formula, and at the same time the geometric stiffness of the initial constant load force is considered, which simulates the geometrical nonlinearity of the cable.

\section{3) Simulation of other components}

For the tower and such elements as piers and foundation, because of their stiffness, the elastic beam unit is used to model directly, and the soil spring is used to simulate pile-soil interaction.

\section{4) The whole bridge finite element discrete model}

Based on the above simulation principle, the section length of each unit is divided according to the principle of easy calculation and guaranteeing the calculation accuracy, and the MIDAS program is used to establish the detailed finite element model. For the whole bridge, there are 2,271 nodes, 4,042 units, of which beam elements are 2,746, truss elements 128 , plate elements 1168 . Its finite element discrete model is shown in Figure VIII.

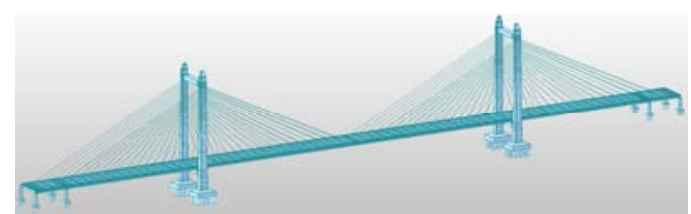

FIGURE VIII. THE DIAGRAM OF THE WHOLE BRIDGE FINITE ELEMENT DISCRETE MODEL
B. Comparative Analysis of Theoretical Values and Measured Values of Vibration Characteristics

1) Comparison of theoretical mode and measured mode

After the precise finite element model is established, the dynamic characteristics of the bridge are calculated and analyzed in the corresponding construction stage, in which the longitudinal deflection of the tower column is the smallest in the natural vibration frequency and belongs to the first-order mode. The bridge vibration data collection and the analysis system are used in this dynamic characteristic test by adopting DASP, the large capacity data acquisition processing analysis platform software and the modal analysis software to carry on the analysis. Through analysis and comparison, it is found that the first-order mode of the structure is unchanged in the cantilever construction, but the frequency of the natural vibration is constantly changing. The first-order theoretical analysis and the measured vibration pattern of the construction phase are shown in Figure IX.

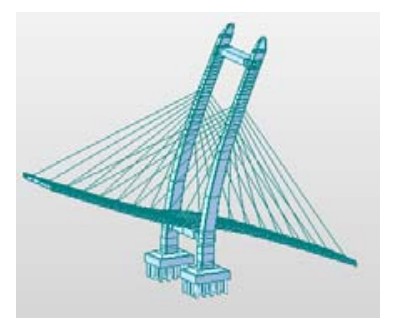

A) THE DIAGRAM OF THEORETICAL VIBRATION MODE

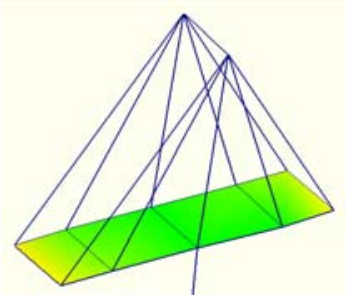

B) THE DIAGRAM OF MEASURED VIBRATION MODE

FIGURE IX. THE DIAGRAM OF FIRST-ORDER THEORETICAL MODE AND MEASURED MODE

2) Comparative analysis of different calculation methods and measured values

The measured damping ratio is between the $0.297 \%$ 8.623 , as a small damped vibration. The theoretical and measured values of the natural frequencies of the construction phase are less than $1 \mathrm{~Hz}$, which falls in the low frequency vibration structure. The theoretical values of the natural frequencies are compared with the measured values in Table I, and the frequency curves for different methods are shown in Figure $\mathrm{X}$. 
TABLE I. COMPARISON OF THEORETICAL VALUES AND MEASURED VALUES OF THE NATURAL FREQUENCIES

\begin{tabular}{|c|c|c|c|c|c|c|c|}
\hline \multirow[b]{2}{*}{ Construction phases } & \multirow{2}{*}{$\begin{array}{l}\text { Calculation value } \\
\text { of finite element } \\
\text { methods }(\mathrm{Hz})\end{array}$} & \multicolumn{2}{|c|}{ Double-mass system } & \multicolumn{2}{|c|}{ Estimation formulas } & \multirow[b]{2}{*}{$\begin{array}{c}\text { Measured } \\
\text { values }(\mathrm{Hz})\end{array}$} & \multirow{2}{*}{$\begin{array}{r}\text { measured } \\
\text { damping } \\
\text { ratios }(\%)\end{array}$} \\
\hline & & $\begin{array}{l}\text { Calculation } \\
\text { values }(\mathrm{Hz})\end{array}$ & $\begin{array}{l}\text { Errors for finite } \\
\text { element methods } \\
(\%)\end{array}$ & $\begin{array}{r}\text { Calculation } \\
\text { values }(\mathrm{Hz})\end{array}$ & $\begin{array}{c}\text { Errors for finite } \\
\text { element methods } \\
(\%)\end{array}$ & & \\
\hline Section No. 0 & 0.299 & 0.298 & 0.3 & 0.254 & 14.95 & 0.369 & 0.452 \\
\hline Section No. 1 & 0.303 & 0.287 & 5.3 & 0.295 & 2.78 & 0.368 & 2.014 \\
\hline Section No. 2 & 0.306 & 0.280 & 8.5 & 0.308 & 0.52 & 0.367 & 0.854 \\
\hline Section No. 3 & 0.306 & 0.272 & 11.1 & 0.310 & 1.47 & 0.360 & 1.003 \\
\hline Section No. 4 & 0.303 & 0.263 & 13.1 & 0.306 & 1.12 & 0.350 & 1.242 \\
\hline Section No. 5 & 0.296 & 0.254 & 14.3 & 0.297 & 0.40 & 0.330 & 0.966 \\
\hline Section No. 6 & 0.287 & 0.244 & 15.1 & 0.284 & 0.94 & 0.315 & 3.410 \\
\hline Section No. 7 & 0.273 & 0.234 & 14.5 & 0.269 & 1.49 & 0.296 & 2.345 \\
\hline Section No. 8 & 0.260 & 0.223 & 14.2 & 0.252 & 3.04 & 0.288 & 2.114 \\
\hline Section No. 9 & 0.246 & 0.213 & 13.5 & 0.235 & 4.66 & 0.272 & 0.832 \\
\hline Section No. 10 & 0.226 & 0.202 & 10.6 & 0.217 & 4.17 & 0.247 & 0.243 \\
\hline Section No. 11 & 0.214 & 0.192 & 10.2 & 0.199 & 6.87 & 0.231 & 5.341 \\
\hline Section No. 12 & 0.195 & 0.182 & 6.5 & 0.183 & 6.28 & 0.221 & 0.756 \\
\hline Section No. 13 & 0.180 & 0.173 & 4.1 & 0.167 & 7.38 & 0.203 & 0.869 \\
\hline Section No. 14 & 0.165 & 0.163 & 1.2 & 0.151 & 8.25 & 0.192 & 0.545 \\
\hline Section No. 15 & 0.153 & 0.155 & 1.3 & 0.139 & 9.34 & 0.172 & 1.706 \\
\hline Section No. 16 & 0.141 & 0.147 & 4.3 & 0.126 & 10.35 & 0.163 & 0.628 \\
\hline
\end{tabular}

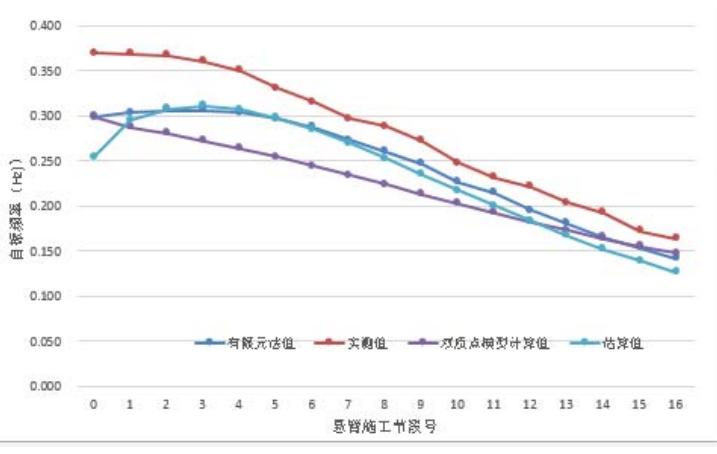

FIGURE X. COMPARISON OF THE THEORETICAL AND MEASURED VALUES OF THE NATURAL VIBRATION FREQUENCY F

The conclusions from Figure $\mathrm{X}$ and Table $\mathrm{I}$ can be reached as follows:

1) From the construction process of Section No. 0 to 16 , the theoretical values and measured values of the natural frequencies after each construction stage tend to be consistent with the increase of construction phase, and its vibration mode of the bridge structure with symmetrical construction is symmetrical or anti-symmetrical, which shows that the calculation model is accurate and reliable when the finite element analysis is used.

2) From the construction process of Section No. 0 to 16 , the theoretical values of the natural frequencies of each construction stage are greater than the measured values, which shows that the bridge structure in construction does not have the quality problems such as defects, and the actual stiffness of the structure is greater than the design stiffness, which meets the design requirements.

3) Along with the construction progress from Section No. 0 to 16 , the weight of the beam gradually increases, and the natural frequency of the tower column's longitudinal deflection decreases gradually and changes in a linear way.

4) As can be seen from the figures, except for Section No. 0, the other 15 construction stages, the errors for the double-mass methods and the estimation methods are very small in calculating the natural frequencies of the cantilever construction phases of the cable-stayed bridge. In comparison of the double-mass methods with the estimation methods, the maximum error of the calculation value is $14.1 \%$. In comparison of the estimation methods with the finite element methods, the maximum error of the calculation value is $14.9 \%$.

\section{CONCLUSION}

By comparing the theoretical values of Qihe Yellow River Bridge with the measured values, it is found that the two basically match with each other, indicating that the construction quality in the construction stage of Qihe Yellow River Bridge and the dynamic performance in the finished stage meet the design requirements. By analyzing the vibration modes and the natural vibration frequencies, 
the construction quality evaluated in the construction stage is enough to meet the design requirements, and the accuracy of theoretical analysis model is further validated. The estimation formula can be used to help bridge builders to make quick judgments of the dynamic characteristics in construction phase of the cable-stayed bridge, which can provide references for the same type of bridge design and construction monitoring.

\section{REFERENCES}

[1] Xiang Haifan, Li Ruilin, Yangc Hangzhong, Approximate Seismic Calculation of Suspension System Of Cable-stayed Bridge [M], Shanghai: Structural Engineer, 1985.

[2] Yuan Wancheng, Yan Dong, Simplified Calculation Method for Longitudinal Drift Frequencies of Cable-stayed Bridge [M], Shanghai: Journal of Tongji University (Natural Science Edition), 2005.

[3] Zhou Yongjun, Zhang Xiaodong, Song Yifan, Zhao Yu, Energy Method Calculation Formula of Longitudinal Vibration Base Frequency of High Pier Continuous Rigid Frame Bridge, Xi ' An: Journal of Chang'an University (Natural Science Edition), 2013.

[4] Rei Junqing, Theory and Application of Long-Span Bridge Structure [M], Beijing: Beijing Jiaotong University Press, 2007;

[5] Li Liankun, structural Mechanics [M], Beijing: Higher Education Press, 2002.

[6] Liang Peng, Xiao Rucheng, Xu Yue, On Mechanical Behavior of Construction Process of Super Long-span Cable-stayed Bridge [J], Xi'an: World Bridge, 2005.

[7] Chen Quankai, Theoretical Analysis and Experimental Study on Dynamic Characteristics of Cable-stayed Bridge with Low Pylon [J], Changsha: China-Foreign Highway, 2014.

[8] Yu Jianyun, He Zhihui, Song Xiaodong, Study on Dynamic Performance of Multi-tower Cable-stayed Bridge in High Speed [J], Nanchang: Railway Standard Design, 2017.

[9] Seed, H.B, Reese, L. C. The Action of Soft Clay A-long Friction Piles [J]. Proc. ASCE, 1955, 81(3): 81-86. 